Mens

Revue d'histoire intellectuelle et culturelle

\title{
Introduction - D'un anti-impérialisme à l'autre : représentations des nations dominées et colonisées au Canada français
}

\section{Maurice Demers}

Volume 13, numéro 1, automne 2012

S’approprier le passé des autres : les usages de l'histoire internationale au Québec avant la Révolution tranquille

URI : https://id.erudit.org/iderudit/1019696ar

DOI : https://doi.org/10.7202/1019696ar

Aller au sommaire du numéro

Éditeur(s)

Centre de recherche en civilisation canadienne-française

ISSN

1492-8647 (imprimé)

1927-9299 (numérique)

Découvrir la revue

Citer ce document

Demers, M. (2012). Introduction - D’un anti-impérialisme à l'autre :

représentations des nations dominées et colonisées au Canada français. Mens,

13(1), 7-18. https://doi.org/10.7202/1019696ar 


\section{Dossier}

\section{S’approprier le passé des autres : les usages de l'histoire internationale au Québec avant la Révolution tranquille}

\section{Introduction - D'un anti-impérialisme à l'autre : représentations des nations dominées et colonisées au Canada français}

Maurice Demers Université de Sherbrooke

Dans la mémoire collective, l'ouverture du Québec sur le monde coïncide avec Expo 67, alors que des millions de visiteurs de Montréal et du reste de la province viennent se dépayser dans les pavillons de nations exotiques, découvrant la culture et la cuisine de pays lointains. Pour Pauline Curien, l'Exposition universelle de Montréal a été une réelle " catharsis identitaire ", confirmant l'ouverture du Québec sur le monde et " parachev[ant] le travail entamé par la Révolution tranquille ${ }^{1}$ ". Certes, les témoignages de Québécois abondent concernant l'importance de leur visite à l'Expo, qui a représenté pour eux une occasion unique de prendre contact

1 Pauline Curien, «Une catharsis identitaire : l'avènement d'une nouvelle vision du Québec à Expo 67 », Anthropologie et Sociétés, vol. 30, nº 2 (2006), p. 129-151. 
avec des cultures non occidentales. Néanmoins, il serait faux de penser que l'internationalisation du Québec d23ébute avec la Révolution tranquille. Cette période de changements accélérés a certainement contribué à transformer les rapports du Québec au monde, légitimant par la doctrine Gérin-Lajoie les interventions du gouvernement québécois sur la scène internationale et amplifiant la circulation de diverses références mondiales dans la province. Cependant, pour ce qui est du processus d'ouverture sur le monde, force est de constater que les communautés religieuses, diverses associations culturelles, ainsi que plusieurs groupes de citoyens avaient depuis longtemps établi des contacts avec des cultures étrangères, et ce, indépendamment des grandes puissances impériales, influençant ainsi les destinées de cette contrée francophone d'Amérique. L'Expo a certes été un événement culturel célébrant l'indéniable modernité de Montréal et son caractère de ville d'envergure mondiale, mais certains de ses aspects rappelaient peut-être également aux plus vieux les expositions missionnaires qui, à leur façon, introduisaient des références culturelles diverses dans le terroir canadien-français. C'est l'époque où, Pierre Beaudet nous le rappelle avec justesse, "l'image des petits Chinois [que les écoliers québécois "achetaient” pour financer l'œuvre de la Sainte-Enfance] pénètre le subconscient populaire avec un mélange de paternalisme, de racisme et de solidarité humaine ${ }^{2}$ ". Cette époque - celle de la "Grande Noirceur "- n'est toutefois pas à rejeter du revers de la main si nous voulons comprendre l'appropriation progressive de références internationales au Québec, incluant des références venant d'un Sud colonisé et dominé 3 . Par exemple, la population de Sherbrooke savait

2 Pierre Beaudet, Qui aide qui? Une brève histoire de la solidarité internationale au Québec, Montréal, Éditions du Boréal, 2009, p. 26.

3 Pour l'actualité du débat sur la Grande Noirceur, voir l'excellente note critique d'Alexandre Turgeon sur le plus récent livre de Jean-Marc Piotte et Jean-Pierre Couture (Alexandre Turgeon, " Se déchirer sur la Révolution tranquille" : Les nouveaux visages du nationalisme conservateur au Québec, de Jean-Marc Piotte et Jean-Pierre Couture, Montréal, Québec Amérique, 2012 ", Bulletin d'histoire politique, vol. 21, no 3 (2013), p. 150-161). 
qu'à la confluence des rivières Magog et Saint-François, en 1919, les religieuses Florina Gervais et Chan Tsi Kwan avaient uni leurs forces pour fonder la congrégation des sœurs Missionnaires de Notre-Dame des Anges (MNDA). Cette fondation pluriculturelle a permis de tisser entre le Québec et la Chine des liens originaux, qui ont favorisé la diffusion de connaissances sur une autre culture en Estrie ${ }^{4}$. De même, les voyages de certains membres de la famille de Lotbinière en Inde ou ceux d'un Honoré Beaugrand au Mexique avaient certainement retenu l'attention de leurs concitoyens, Hector Joly de Lotbinière et Honoré Beaugrand ayant notamment exercé des fonctions politiques importantes au Québec à la fin du XIX ${ }^{\mathrm{e}}$ siècle ${ }^{5}$. Ces expériences transnationales s'inscrivent généralement dans des rapports de pouvoir inégaux et révèlent, la plupart du temps, des attitudes ouvertement impérialistes. Néanmoins, des brèches dans cette expérience canadienne-française à l'international ont permis l'émergence d'une lecture originale des cultures métissées du tiersmonde et ont même incité certains auteurs à reconnaître le reflet bien que lointain - de la réalité canadienne-française dans l'histoire de ces contrées asservies par l'impérialisme, conduisant ainsi à une appréciation nouvelle de la lutte des peuples dominés de la terre bien avant la Révolution tranquille. Ces parcours enchevêtrés laissent entrevoir des façons de revisiter le processus d'ouverture du Québec sur le monde, ce que proposent les trois textes de ce dossier en analysant la représentation de l'histoire latino-américaine, indienne et africaine au Canada français dans les deux premiers tiers du $\mathrm{xx}^{\mathrm{e}}$ siècle.

La nature des relations entre les Canadiens français et les habitants de nations soumises économiquement et politiquement aux intérêts des grandes puissances pouvait influencer positivement ou négativement les représentations véhiculées au Québec et susciter un sentiment

\footnotetext{
${ }^{4}$ S. Gilberte Giroux, mnda, Mère Marie-Gabriel, Co-fondatrice des seurs Missionnaires de Notre-Dame des Anges (1899-1974), Montréal, Imprimerie des Franciscains, 1983.

${ }^{5}$ Voir les textes de Serge Granger et de Maurice Demers pour les références relatives à ces deux exemples.
} 
d'ouverture ou de supériorité face à l'Autre. D'une manière ou d'une autre, ces représentations de nations étrangères, petites et grandes, participaient à une certaine forme d'internationalisation de la pensée, et ce, d'une façon bien différente des références relatives aux coutumes des centres impériaux qui dictent les normes de la haute culture que tentent d'acquérir et de transmettre les élites canadiennes-françaises. L'identification des logiques sous-tendant les représentations des cultures "non impériales " peut jeter un éclairage novateur sur la société qui les produit. Comment ces représentations positionnentelles le Canada français par rapport au territoire comparé? Que nous révèlent-elles sur le Québec d'avant la Révolution tranquille et son rapport au monde et, en particulier, aux autres peuples dominés de la planète? La représentation a-t-elle plus tendance à calquer l'image de l'Asie, de l'Afrique et de l'Amérique latine véhiculée dans les grands centres de pouvoir de la planète (que ce soit Paris, Rome, Londres ou Washington)? Dénote-t-on une idiosyncrasie canadiennefrançaise? Un désir, par la représentation de l'Autre, d'établir de nouvelles formes de solidarité? Ce dossier espère apporter un éclairage novateur à ces interrogations.

Déjà dans l'entre-deux-guerres, Marc Bloch en appelait à ce que l'on utilise davantage «l'histoire comparée [pour] dégager "l'originalité" des différentes sociétés ${ }^{6} »$. Qu'il ait été inspiré du comparatisme de Bloch, de l'histoire braudélienne des réseaux de relations ou encore, plus récemment, de l'émergence de l'histoire globale, le regard de plusieurs historiens et historiennes a traversé les frontières nationales de bon gré depuis la fin de la Première Guerre mondiale afin de remettre en question certains a priori de l'histoire dite "officielle». Cette pratique de l'histoire débordant du strict cadre de l'État-nation que ce soit dans ses approches comparatives, connectées, transnationales ou transculturelles - a surtout été exercée dans le but de revisiter l'histoire des grandes puissances de ce monde. Les études postcoloniales

${ }^{6}$ Marc Bloch, "Pour une histoire comparée des sociétés européennes ", Mélanges historiques, Paris, SEVPEN, [1928] 1963, p. 27. 
et le tournant culturel dans les sciences humaines ont donné une nouvelle impulsion à cette ambition. Homi Bhabha écrivait d'ailleurs :

La métropole occidentale doit affronter son histoire postcoloniale, racontée par son afflux de migrants et de réfugiés de guerre, comme un récit indigène interne à son identité nationale; et la raison en est clairement exprimée dans les mots ivres, balbutiés, de Mr. "Whisky " Sisodia dans les Versets sataniques: "L'ennui avec les Angang Anglais, c'est que leur hishis histoire s'est passée outremer, alors ils ne savent papa pas ce qu'elle signifie $»^{7}$.

Les chercheurs en sciences humaines inscrivant leurs recherches dans le sillage des études postcoloniales ont, à juste titre, cherché à remettre en question l'histoire des puissances impérialistes. Leur regard s'est aussi tourné vers les sociétés qui ont été transformées par ces puissances dominantes, dans le but de revoir leur mode d'interaction avec les centres de pouvoir. Le travail des chercheurs a pris en compte les processus d'hybridation dans le tiers-monde qui ont favorisé la création de nouvelles formes "d'articulations entre modernité et postmodernité, entre culture et pouvoir ", en redéfinissant le rapport au monde par une "offre symbolique hétérogène, renouvelée par une constante interaction du local avec des réseaux nationaux et transnationaux ${ }^{8}$ ». Cette approche laisse entrevoir une perspective plus décentrée des rapports de pouvoir, permettant une meilleure compréhension des rapports Sud-Sud, qui ont redéfini le monde contemporain depuis la conférence de Bandung en 1955. Ainsi, l'intérêt pour le Québec de sonder son histoire qui "s'est passée outremer " est tout aussi pertinent afin de déterminer quels types de rapports ont été établis entre les francophones d'Amérique du Nord et les peuples étrangers (colonisés ou non), quels types de transferts culturels la présence canadienne-française à l'étranger a

7 Homi K. Bhabha, "Introduction ", Les lieux de la culture : une théorie postcoloniale, Paris, Payot, [1994] 2007, p. 37. Dans cet extrait, Bhabha cite Salman Rushdie, The Satanic Verses: a Novel, Londres, Viking Penguin Inc., 1988, p. 343.

${ }^{8}$ Néstor García Canclini, Cultures hybrides : stratégies pour entrer et sortir de la modernité, Québec, Les Presses de l’Université Laval, [1989] 2010, p. 292-293. 
suscités. Cette analyse permettra aussi de voir de quelle manière la comparaison entre l'histoire de la nation québécoise et celle d'autres contrées conquises et dominées peut jeter un éclairage novateur sur les processus historiques ayant façonné le monde contemporain. Bref, en examinant comment le Canada français d'avant la Révolution tranquille s'est approprié l'histoire de l'Amérique latine, de l'Afrique et de l'Inde, les chercheurs qui ont participé à ce dossier contribuent à cerner l'originalité de cette représentation de l'histoire des peuples métissés et du monde colonisé. Leur travail permet aussi de mieux apprécier les références étrangères qui ont circulé au Québec, en les situant au-delà des héritages identifiés par Yvan Lamonde et illustrés par la formule : $\mathrm{Q}=-(\mathrm{F})+(\mathrm{GB})+(\mathrm{USA})^{2}-(\mathrm{R})+(\mathrm{C})^{9}$.

Lamonde n'a certes pas voulu que l'exploration s'arrête à ses références principales. Par le concept d'américanité qui englobe tant "l'Amérique latine que l'Amérique anglo-saxonne », il a tenté de montrer comment les autres nations d'Amérique ont influencé la culture québécoise et ont facilité "son consentement à son appartenance continentale ${ }^{10}$ ". Gérard Bouchard, coauteur avec Lamonde de La nation dans tous ses états : le Québec en comparaison ${ }^{11}$, a poursuivi dans ses propres recherches la mise en parallèle de l'histoire du Québec

9 Par cette formule, Lamonde postule que le Québec a été façonné par de multiples héritages. La France $(\mathrm{F})$ a certes joué un rôle primordial, mais probablement moins important que ce qui avait été avancé par les élites traditionnelles canadiennesfrançaises, la culture de la Grande-Bretagne (GB) et des États-Unis (USA) ayant aussi joué un rôle significatif. Lamonde illustre d'ailleurs l'importance de cette dernière référence en lui apposant un exposant. Rome (R) demeure une influence importante, mais peut-être moins que ce que suggérait le clergé catholique. Finalement, Lamonde rectifie la première mouture de cette équation en y ajoutant l'influence de la culture canadienne (Yvan Lamonde, Allégeances et dépendances: l'histoire d'une ambivalence identitaire, Montréal, Éditions Nota bene, 2001, p. 8).

${ }^{10}$ Yvan Lamonde (Ni avec eux ni sans eux : le Québec et les États-Unis, Montréal, Nuit blanche éditeur, 1996, p. 11) cité par Olivier Dard dans la préface du livre d'Olivier Dard et Hans-Jürgen Lüsebrink (dir.), Américanisation et antiaméricanisme comparés, Lille, Presses universitaires du Septentrion, 2008, p. 14.

11 Yvan Lamonde et Gérard Bouchard, La nation dans tous ses états : le Québec en comparaison, Montréal, L'Harmattan, 1997. 
avec celle des autres nations d'Amérique. Son essai Genèse des nations et cultures du Nouveau Monde, qui effectuait des rapprochements entre la transformation de la culture québécoise et le parcours d'autres sociétés dites " neuves", se voulait un véritable " plaidoyer en faveur de l'histoire comparative ${ }^{12}$ ». Le résultat final, quoique critiqué, a eu pour effet d'encourager une nouvelle génération de chercheurs à poursuivre l'exploration de l'histoire du Québec en l'intégrant à un cadre élargi, à comparer cette nation à d'autres cultures similaires en incluant son histoire politique et intellectuelle dans l'espace atlantique ou encore, à établir diverses trames transnationales qui ont traversé et influencé les mouvements sociaux québécois ${ }^{13}$. Considérant la filiation britannique des institutions politiques québécoises, il est compréhensible qu'une veine particulièrement fertile de ce courant comparatiste au Québec ait été l'inscription de l'évolution sociopolitique québécoise durant le siècle des nationalités dans l'espace atlantique (anglo-saxon et français). Les travaux de Marc Bellavance, Louis-Georges Harvey et Michel Ducharme ont été particulièrement éclairants à cet égard, dans la mesure où ils ont fait ressortir la simultanéité des luttes canadiennes-françaises avec celles d'autres peuples inspirés par les mêmes idées républicaines et les mêmes sentiments nationalitaires ${ }^{14}$. Le vert et le bleu de Simon Jolivet, quant à lui, pousse la comparaison jusqu'au tournant $\mathrm{du} \mathrm{xx}^{\mathrm{e}}$ siècle en

12 Gérard Bouchard, Genèse des nations et cultures du Nouveau Monde : essai d'histoire comparée, Montréal, Éditions du Boréal, 2001, coll. "Boréal compact ».

13 Frédéric Boily esquissa un portrait brillant des avancées et des hésitations de cette approche au Québec il y a quelques années, plaidant particulièrement pour « la fécondité de l'approche inter provinciale pour comprendre la nature de certains processus politiques passés " (Frédéric Boily, " Plaidoyer pour l’analyse comparée : le Québec et la comparaison ", Bulletin d'histoire politique, vol. 15, nº 3 (printemps 2007), p. 127-140).

14 Marcel Bellavance, Le Québec au siècle des nationalités, essai d'histoire comparée, Montréal, VLB éditeur, 2004 ; Louis-Georges Harvey, Le printemps de l'Amérique française : américanité, anticolonialisme et républicanisme dans le discours politique québécois, 1805-1837, Montréal, Éditions du Boréal, 2005; Michel Ducharme, Le concept de liberté au Canada à l'époque des révolutions atlantiques : 1776-1838, Montréal, McGill-Queen's University Press, 2010. 
analysant la trame historique connectée des sociétés catholiques irlandaise et canadienne-française. Cette exploration des « répercussions [de la question politique irlandaise] en terre québécoise ${ }^{15}$ » met en lumière avec brio la part de l'autre dans l'évolution de l'identité canadienne-française. Malgré le fait que les sociétés étudiées dans ce présent dossier n'ont pas connu une immigration au Québec similaire à celle en provenance de l'Irlande, la présence canadienne-française dans ces contrées lointaines avant le plein déploiement de la Révolution tranquille (une présence non gouvernementale en général) a contribué à tisser de multiples formes d'interactions (et d'interdépendances) qui expliquent pourquoi les questions politiques latino-américaines, indiennes et africaines ont trouvé un écho ici ${ }^{16}$.

L'exploration de ces liens transnationaux nous pousse à considérer le rôle des acteurs non institutionnels dans les relations internationales surtout en ce qui a trait aux relations culturelles et religieuses. L'analyse, dans ce dossier, de l'appropriation de l'histoire des autres par des auteurs comme André Laurendeau ou Dostaler O'Leary, qui ont montré comment l'histoire du Canada français partage des traits communs avec l'histoire d'autres nations soumises politiquement et économiquement, nous amène sur la voie de l'histoire connectée, une approche développée en grande partie par Sanjay Subrahmanyam et Serge Gruzinski afin de conceptualiser les interactions transnationales dans une perspective moins eurocentriste ${ }^{17}$. Les études transnationales,

15 Simon Jolivet, Le vert et le bleu : identité québécoise et identité irlandaise au tournant $d u$ XXe siècle, Montréal, Les Presses de l'Université de Montréal, 2011, p. 31.

16 À l'instar de ce que Serge Granger avait déjà montré à propos de la Chine dans son livre Le lys et le lotus: les relations du Québec avec la Chine de 1650-1950, Montréal, VLB éditeur, 2005.

17 Serge Gruzinski fait ressortir, dans ses plus récentes recherches, les connexions entre des parties du monde aussi différentes que l'Asie et l'Amérique latine en ébauchant une histoire globale de la Renaissance. Il écrit : "C'est au XVI ${ }^{\mathrm{e}}$ siècle que l'histoire humaine s'inscrit sur une scène qui s'identifie avec le globe. C'est alors que les connexions entre les parties du monde s'accélèrent : Europe/Caraïbes à partir de 1492, Lisbonne/Canton à partir de 1513, Séville/Mexique dès 1517, etc. Ajoutons une autre raison qui est au cœur de ce livre : c'est avec la mondialisation ibérique que l'Europe, le Nouveau Monde et la Chine deviennent des partenaires 
au sens large, ont aussi contribué à renforcer cette perspective et ont permis des avancées importantes dans la compréhension de multiples phénomènes se déroulant au-delà du strict cadre de l'État-nation. Pensons simplement au capitalisme, aux migrations et aux communautés transfrontalières, à la circulation des idées et de la culture, à la diffusion des mouvements religieux, à la prolifération des organisations non gouvernementales et de mouvements sociaux ayant une portée mondiale, etc. À cet égard, Peggy Levitt et Sanjeev Khagram notent que la mise en place de mouvements transnationaux par des acteurs de la société civile "creates a space to imagine options for social transformation that are obscured when borders, boundaries, and the structures, processes, and actors within them are taken as given ${ }^{18}$ ". Cette possibilité de transformation sociale créée par un cadre référentiel transnational (prenant en compte des idées et des pratiques émanant du Sud et, plus largement, des mouvements de décolonisation, et pas seulement celles venant des grandes puissances atlantiques) a surtout été explorée au Québec par des chercheurs dont les travaux portaient sur les années 1960. À ce titre, Ivan Carel note avec justesse que « le Groupe de recherche interuniversitaire sur le Québec des années 1960 et ses relations extérieures (GRIQueRE) [a mis] de

planétaires. " Le présent dossier met en évidence une certaine appropriation de l'histoire internationale au Québec aux $\mathrm{XIX}^{\mathrm{e}}$ et $\mathrm{Xx}^{\mathrm{e}}$ siècles, période qui consacre ces connexions planétaires évoquées par Gruzinski. Pour la citation, voir Serge Gruzinski, L'Aigle et le Dragon : démesure européenne et mondialisation au XVI siècle, Paris, Fayard, 2012, p. 12. Pour d'autres textes pertinents à propos de l'histoire connectée, voir : Sanjay Subrahmanyam, «Connected Histories: Notes Towards a Reconfiguration of Early Modern Eurasia ", dans Victor Lieberman (dir.), Beyond Binary Histories: Re-imagining Eurasia to c.1830, Ann Arbor, The University of Michigan Press, 1997, p. 289-315; Serge Gruzinski, "Les mondes mêlés de la Monarchie catholique et autres "connected histories" ", dans Annales : histoire, sciences sociales, 56 ${ }^{\mathrm{e}}$ année, $\mathrm{n}^{\circ} 1$ (2001), p. 85-117; Aline Charles et Thomas Wien, "Le Québec, entre histoire connectée et histoire transnationale ", Globe : revue internationale d'études québécoises, vol. 14, nº 2 (2011), p. 199-221.

18 Peggy Levitt et Sanjeev Khagram, "Constructing Transnational Studies: An Overview ", dans Peggy Levitt et Sanjeev Khagram (dir.), The Transnational Studies Reader: Intersections \& Innovations, New York, Routledge, 2008, p. 9. 
l'avant la nécessité d'étudier dans un premier temps l'influence que les mouvements étrangers ont pu avoir au Québec ${ }^{19}$ ». Sean Mills a habilement relevé ce défi dans son livre Contester l'empire, dans lequel il décortique les multiples influences transnationales qui traversent alors les mouvements sociaux contestataires montréalais. Il consacre en outre un chapitre à l'analyse de " la dimension internationale de la résistance " québécoise ${ }^{20}$. Mills souligne l'ampleur et les limites de l'appropriation au Québec de la pensée contestataire issue des divers mouvements internationaux d'affirmation des droits civiques et de décolonisation. Il faut dire que les transferts culturels résultant de cette rencontre avec l'Autre dominé et colonisé ont souffert d'un processus de sélection et d'interprétation qui a parfois théâtralisé les doléances des «damnés de la terre » pour mieux les arrimer à la réalité québécoise. Néanmoins, l'analyse de ce processus de sélection et de traduction des divers mouvements de contestation anti-impérialistes que l'on cherchait à diffuser au Québec est des plus pertinentes. Comme le notaient récemment Stéphanie Danaux et Nova Doyon, tout transfert culturel « repose sur le désir d'affirmation identitaire de la culture d'accueil, lequel révèle généralement, selon les cas, une volonté de différenciation ou d'intégration à un ensemble culturel plus vaste dont la légitimité est reconnue ${ }^{21}$ ». L'affirmation nationale des Canadiens français s'étant abreuvée au fil des siècles tant de contestation des grands empires coloniaux que de collaboration avec ceux-ci, il est d'autant plus pertinent d'examiner quel traitement a été réservé à l'histoire des contrées soumises économiquement et politiquement aux intérêts des grands centres de pouvoir. Cela nous permettra d'évaluer si les auteurs étudiés agissent en tant que passeurs

19 Ivan Carel, "Les années 1960 : émergence d'une perspective internationaliste ", Bulletin d'histoire politique, vol. 16, $\mathrm{n}^{\circ} 2$ (hiver 2008), p. 133-136.

20 Sean Mills, Contester l'empire : pensée postcoloniale et militantisme politique à Montréal, 1963-1972, Montréal, Hurtubise HMH, [2010] 2011.

21 Stéphanie Danaux et Nova Doyon, «Introduction : l'étude des transferts culturels en histoire culturelle", Mens : revue d'histoire intellectuelle et culturelle, «Dossier Enjeux et modalités des transferts culturels dans la vie artistique canadiennefrançaise de la première moitié du xx $x^{\mathrm{e}}$ siècle ", vol. XII, n 2 (printemps 2012), p. 9. 
culturels cherchant à transmettre aux lecteurs une histoire engagée, qui établit des connexions entre l'histoire des nations sur lesquelles se portent leur intérêt et la leur, suggérant par le fait même les voies de la résistance et de l'autodétermination.

Les trois textes de ce dossier portent sur « les trajectoires et les influences culturelle ${ }^{22}$ " latino-américaines, indiennes et africaines qui ont traversé le Canada français avant la Révolution tranquille. Ils analysent la transformation du discours sur l'Autre que l'on retrouve dans les écrits canadiens-français et précisent quels aspects de l'expérience historique des nations étudiées les auteurs choisissent de faire ressortir afin qu'ils trouvent écho au Canada français. Par exemple, l'article de Maurice Demers, intitulé « De l'exotisme à l'effet miroir : la représentation de l'histoire latino-américaine au Canada français ", illustre comment des auteurs nationalistes canadiensfrançais en sont venus à tisser dans leurs écrits la trame d'une histoire connectée des peuples "latins " d'Amérique. Cet article révèle comment l'instrumentalisation du passé latino-américain - surtout l'histoire de sa résistance face à l'impérialisme anglo-saxon - a servi les fins d'un discours anti-impérialiste d'autodétermination qui émerge dès l'entre-deux-guerres. Serge Granger, pour sa part, jette un éclairage novateur sur la question de l'émergence du discours de la décolonisation au Québec, dans son texte intitulé " L'Inde et la décolonisation au Canada français ", en analysant les reportages publiés au Québec sur l'indépendance de cette ancienne colonie britannique à la fin des années 1940. Il fait ressortir une appréciation originale pour l'époque de cet événement charnière de l'histoire mondiale. Finalement, Éric Desautels nous fait part des particularités d'un orientalisme à la québécoise dans son texte portant sur les références africaines dans le discours missionnaire. Intitulé " La représentation sociale de l'Afrique dans le discours missionnaire canadien-français (19001968) ", cet article retrace une composante essentielle du discours québécois sur ce continent avant qu’une nouvelle appréciation tiers-

22 Charles et Wien, "Le Québec, entre histoire connectée et histoire transnationale ", p. 206. 
mondiste ne vienne profondément transformer la représentation des mouvements politiques autonomistes et anti-impérialistes africains. Ces trois articles devraient nous aider à revisiter le processus historique d'ouverture du Québec aux références provenant du tiers-monde. 